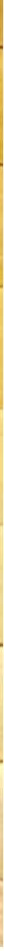

Tradição Clássica e Historiografia da Arte na obra Padre Jesuíno do Monte Carmelo de Mário de Andrade

Classical Tradition and Art Historiography in the book Padre Jesuíno do Monte Carmelo by Mário de Andrade

\author{
Ms. Myriam Salomão
}

Como citar:

SALOMÃO. M. Tradição Clássica e Historiografia da Arte na obra "Padre Jesuíno do Monte Carmelo" de Mário de Andrade. MODOS. Revista de História da Arte. Campinas, v. 4, n.2, p.181-194, mai. 2020. Disponivel em: <https://www.publionline.iar.unicamp.br/index.php/ mod/article/view/4586>

DOI: https://doi.org/10.24978/mod.v4i2.4586.

Imagem: Santos Carmelitas, detalhe da pintura do forro da nave da igreja da Venerável Ordem Terceira do Carmo, da cidade de São Paulo/ SP. Autoria: Padre Jesuíno do Monte Carmelo. Fotografia: autora, dez. 2011. 


\title{
Tradição Clássica e Historiografia da Arte na obra Padre Jesuíno do Monte Carmelo de Mário de Andrade
}

\author{
Classical Tradition and Art Historiography in the book Padre Jesuíno do \\ Monte Carmelo by Mário de Andrade
}

\author{
Ms. Myriam Salomão*
}

\begin{abstract}
Resumo
Pretendemos identificar, analisar e estabelecer possíveis relações do uso de textos da historiografia da arte sobre a tradição clássica presentes e citados direta ou indiretamente no livro Padre Jesuíno de Monte Carmelo (1945), de autoria de Mário de Andrade, textos estes que possivelmente foram utilizados para a construção dos argumentos na biografia e análises das obras do padre pintor. Nesse estudo identificamos as citações a artistas do Renascimento e Barroco e como elas foram utilizadas na construção do texto biográfico. Concomitantemente, destacamos trechos que remetem à presença de linhas teóricas da história e estética da arte. A partir da identificação das citações, verificamos a quais obras ou autores elas pertenciam e se estas integram o acervo de livros remanescentes da biblioteca particular de Mário de Andrade, atualmente pertencente ao Instituto de Estudo Brasileiros na Universidade de São Paulo.
\end{abstract}

\section{Palavras-chave}

Mário de Andrade. Padre Jesuíno do Monte Carmelo. Historiografia da Arte. Tradição Clássica. Estética e História da Arte.

\begin{abstract}
This paper aims to identify, analyze and establish possible relations of the use of texts from the historiography of art on the classical tradition presented and mentioned directly or indirectly in the book Padre Jesuíno de Monte Carmelo (1945), written by Mário de Andrade, texts which were possibly used for the construction of the arguments in the biography and analysis of the works of the painter priest. In this paper, we identify the quotes to artists from the Renaissance and Baroque and how they were used in the construction of the biographical text. Concomitantly, we highlight excerpts that refer to the presence of theoretical lines of art history and aesthetics. From the identification of the citations, we verified which works or authors they belonged to and also if they are part of the collection of remaining books from the private library of Mário de Andrade, currently at the Instituto de Estudos Brasileiros at the Universidade de São Paulo.
\end{abstract}

\section{Keywords}

Mário de Andrade. Padre Jesuíno do Monte Carmelo. Art Historiography. Classical Tradition. Aesthetics and Art History. 
A expressão tradição clássica em geral remete à Antiguidade Clássica, para a descendência da arte da Grécia e de Roma, fazendo uso do repertório de formas - visuais, arquitetônicas, literárias desenvolvido por estas culturas, sendo pertinente afirmar que o legado clássico foi fundamental para 0 desenvolvimento das áreas do conhecimento que hoje denominamos História da Arte: não por acaso, Erwin Panofsky (1892-1968) escolheu chamar a História da Arte de uma disciplina humanística, ligandoa a uma tradição cujo passado poderia ser seguido até o Renascimento e a Antiguidade1.

Nesse processo, o nome de Giorgio Vasari (1511-1574) se reveste de importância considerável devido à publicação, em 1550, de Vite dei più eccelenti pittori, scultori e architettori italiani, com segunda edição ampliada em 1568. Nessa obra, Vasari dispõe os artistas que o precederam ou que the são contemporâneos numa perspectiva histórica. Às pesquisas biográficas juntam-se as listas de obras e de anedotas ou lendas. A atualidade de Vasari reside no fato de seu livro apresentar uma ideia evolutiva e progressiva da História aplicada à Arte, da Idade Média até Michelangelo. Essa concepção faz-se acompanhar de um método biográfico que terá igualmente grande aceitação.

Mas é preciso destacar que a noção de história da arte aparece pela primeira vez somente em 1764, na página de rosto da Geschichte der Kunst des Altertums, de Johann Joachim Winckelmann (17171768). Obra-prima dos estudos sobre o mundo antigo, o livro destinava-se a revitalizar a pertinência do legado clássico para a Alemanha, proclamando a superioridade da arte e da cultura gregas e combinando descrições extasiadas de obras individuais com análise histórica. Portanto, foi justamente no universo de língua germânica, ao lado da História, fermentada pela prática antiquária ${ }^{2}$, pela Arqueologia e em diálogo tensionado com a Crítica de Arte, com a Crítica Literária e com a Estética que surgiu a Historiografia da Arte, acontecimento marcado pela criação da primeira cátedra de História da Arte, em meados do século XIX, quando outras cadeiras destinadas à pesquisa no campo também se disseminaram por toda a Europa (Chilvers, 2001: 572).

A trajetória da disciplina divide-se, desse modo, entre os atributos do legado clássico e o diálogo com a emergência de novas concepções de saber e do próprio estabelecimento de uma cultura vinculada à modernidade que ultrapassa as fronteiras da Europa e se instala também na América. A repercussão no Brasil nos leva a afirmar que Mário de Andrade investiu decisivamente nos estudos dos homens de letras da época moderna, na certeza de que havia ligações profundas entre a retomada do idioma e da literatura greco-latinas como língua franca da "cidade letrada" humanista e as figurações visuais realizadas pelos artistas daquela época, transmigrando estas questões para o estudo da arte colonial como a tradição clássica possível na arte brasileira.

Mário Raul de Morais de Andrade (1893-1945), ou simplesmente Mário de Andrade, foi o principal articulador da Semana de Arte Moderna de 1922 na cidade de São Paulo, sendo definido por Telê Lopez como:

Polígrafo: - poeta, ficcionista, crítico literário, das exposições, dos concertos e recitais, do cinema, no ofício de jornalista que também escrevia crônicas (um número prodigioso), musicólogo, historiador das artes plásticas e da arquitetura incursionando na esfera da estética, correspondente fecundo em contato com os nomes mais significativos do campo cultural de sua época, pesquisador do folclore do Brasil capaz de reflexões teóricas a propósito do que registrava - professor no Conservatório e na Universidade do Distrito 
Federal, fotógrafo, intelectual voltado para projetos culturais democráticos e renovadores, principalmente quando dirigiu o Departamento de Cultura da cidade de São Paulo, criador do Serviço do Patrimônio Histórico e Artístico Nacional, Mário de Andrade é considerado o pai da moderna cultura brasileira. Figura de proa do modernismo nos anos 20, moderno, logrou transcender a estratégia de um programa, de um grupo (Lopez, 2002: 45-46).

Apresenta, em seus textos de crítica histórica e artística, extensa quantidade de leituras que ultrapassam as apresentadas na bibliografia das obras, unindo a sua visão pessoal com a de autores lidos. Há citações diretas, com a do nome de um autor ou uma obra no texto. Mas, na maioria das vezes, são indícios, pequenos sinais das leituras sobre um autor, um filósofo, um cientista, um artista plástico, uma personagem mitológica ou histórica.

Claudéte Kronbauer (1993: 13) quando da edição do livro $A$ arte religiosa no Brasil ${ }^{3}$, que reuniu 0 conjunto de crônicas escritas por Mário e publicadas incialmente na Revista do Brasil em 1920, já nos avisava: "o fato de mencionar suas outras fontes no estudo dos festejos - Martius e Manoel Pirajá da Silva - revela o pesquisador que faz questão e sempre fará em reconhecer 0 apoio bebido em autores e obras". Estes textos chamados de "juvenis" pela autora, pois foram escritos quando tinha cerca de 25 , 26 anos de idade; não apresentam imaturidade, pelo contrário, os "textos funcionam como crônica e como historiografia acompanhada de crítica" (Kronbauer, 1993: 12).

Em diversos trechos de A arte religiosa no Brasil, Mário de Andrade (1993) já faz uso de diversas referências a um conhecimento da cultura clássica, fazendo citações como: "O conhecimento e o gozo da Arte é apenas justificável: é necessário ao homem; assumindo ela assim não só a aparência de um luxo, como a caracteriza Reinach4..." (Andrade, 1993: 35). Mário possuía em sua biblioteca um exemplar traduzido, comentado e adaptado para o francês por Salomon Reinach (1858-1932) a partir do original da obra sobre estudos clássicos do historiador inglês James Gow (1854-1923) Minerva: introduction à l'étude des classiques scolaires grecs et latin 5 . Mais à frente, continua demonstrando seu conhecimento clássico e erudito, fazendo breves referências a Tertuliano, Orígenes e às estatuas criselefantinas de Fídias (Andrade, 1993: 41). Cita o italiano Sansovino (Ibidem: 48), sem especificar se Andrea (c.1467/70-1529) ou Jacopo (1486-1570), e na página 57 cita ainda o italiano Giovanni Battista Tiepolo (1696-1770) (Ibidem: 57), pintor esse que será citado novamente no livro Padre Jesuíno de Monte Carmelo, em 1945.

Outro exemplo do estilo de citação a artistas consagrados da história da arte ocidental que Mário de Andrade utiliza para estabelecer comparações com a brasileira está nos textos de 1920, quando coloca dois pintores baianos, Antonio Joaquim Franco Velasco (1780-1833) e José Teófilo de Jesus (17581847) em uma posição mais humilde diante de pintores europeus Eugène Delacroix (1798-1863) e Giovanni de Fiesole, mais conhecido como Fra Angelico (1395-1455), mas sem deixar de destacar suas virtudes: "Se Velasco é Delacroix, Teófilo de Jesus é Fra Angélico, - naturalmente descontadas as proporções. O primeiro é comparável ao mestre francês pelo vigor, o último ao freire florentino pela pureza da intenção" (Ibidem: 58). 
É importante destacar que esse método de escrita, citando a tradição clássica consolidada para criar uma nova, confirmou-se no texto de 1945 sobre o Padre Jesuíno, como apresentaremos mais a frente.

Concluindo suas considerações sobre arte religiosa brasileira e relacionando-a com a tradição italiana através de Lucca della Robbia (1399/1400-1482), Donatello (1385/6-1466), Rafael Sanzio (1483-1520), e estendendo para 0 artista flamengo Peter Paul Rubens (1577-1640) - que também podemos considerar clássico quando pensamos no Barroco -, Mário de Andrade escreve como que pedindo desculpas às figuras dos anjos esculpidos em madeira de diversas igrejas, mas exaltando as qualidades daqueles realizados na igreja dos franciscanos da cidade do Rio de Janeiro:

\begin{abstract}
Sobremodo notável é a teoria dos anjinhos duma beleza ideal, celestiais, puríssimos, quase que única exceção em todo o entalhe nacional. Os nossos artistas em madeira representaram sempre mal a figura humanizada dos anjos; (...) S. Francisco adianta-se muito, nesse terreno, das suas irmãs; e lá vi feições duma pureza tão irreal, que sofreriam confronto com os anjinhos dos mestres - seja Dela Robbia ou Donatelo, Rubens ou Rafael. Não exagero. Comparo anjos com anjos: e buscareis em vão entre os querubins do Presépio de Dela Robbia ou entre as crianças da Ronda de Donatelo beleza mais inocente que uma sublime carinha de madeira dourada que entesta o túmulo do Bourbon, na capela primitiva da Ordem (Ibidem: 71.$)$
\end{abstract}

Telê Ancona Lopez (2002: 46), ao estudar as notas nas margens de determinados livros da biblioteca pessoal de Mário de Andrade 6 , com o objetivo de "focalizar as bibliotecas na complexa teia de obras (e de autores) 'qui entoure et suscite l'acte de la création', que se estende em muitas direções", destaca 0 processo de criação do escritor em relação a outros autores:

Nas influências reconhecidas, nas leituras declaradas, na presença de determinadas obras na biblioteca de um escritor, nas notas autógrafas à margem de suas leituras ou em folhas anexadas a volumes, em todas as formas e feições de recriar, insinuam-se matrizes, instaurando o diálogo que traz a interdisciplinaridade da criação. As matrizes mostram-se de forma principal quando se ligam ao modo de formar; quando textos ou elementos de um texto - temas, motivos, sequências, cenas, personagens, marcos do espaço, do estilo, etc. - enraízam a (re)criação que se afirma como originalidade e autonomia ao integrar outro texto. (Ibidem: 48).

Em dezembro de 1945, alguns meses depois da morte do escritor Mário de Andrade, foi lançada a primeira edição de seu livro Padre Jesuíno do Monte Carmelo, publicado pelo Serviço do Patrimônio Histórico e Artístico Nacional, atual IPHAN. Resultado de extensas pesquisas por ele realizadas entre os anos de 1941 e 1944, é a mais completa pesquisa sobre a vida e obra do pintor colonial paulista padre Jesuíno do Monte Carmelo (1764-1819), que trabalhou em igrejas nas cidades de Santos, São Paulo e ltu.

No livro dividido em três partes: 1 - A Vida: biografia, origens, vida social e religiosidade; 2 - A Obra: levantamento de obras remanescentes e análises estéticas das mesmas e 3 - Notas, Mário desenvolve a narrativa biográfica apoiado por pesquisa histórica e documental, mas em carta de 1944 ao amigo e diretor do SPHAN, Rodrigo Mello Franco de Andrade, conta da dificuldade de escrever evitando a forma poética e literária: 
Desconfio que eu não nasci pra trabalhos como este, a "invenção" trabalha demais. ( ... ) Parece absurdo mas é a mais assustadora das verdades.

Eu decerto nasci pra mentir ... como os poetas. Ou consertando: nasci pra ultrapassar as verdades, que fica mais agradável (Andrade, 1981: 180).

A despeito de todo debate existente sobre as questões psicológicas e literárias na constituição do texto sobre o padre Jesuíno, apontada inclusive pelo próprio Mário de Andrade já na introdução do livro: "É tamanha a incerteza, tal à fuga das datas e tão apaixonante a Vida do padre Jesuíno do Monte Carmelo, que não evitei Ihe dar expressão literária" (Andrade, 1945: 5), ao mesmo tempo, apresenta em sua defesa um referencial teórico: "Mas recentemente, lendo Álvaro Lins, vi George Santayana reconhecendo que a História, se por um lado é ciência na tradução dos documentos, é também "arte dramática" pelo em que é obrigada a personalizar as ideias e as paixões dos mortos (Ibidem).

George Santayana (1863-1952) foi um filósofo, humanista e poeta norte-americano. Seus dois livros, The Sense of Beauty (1896) e The Life of Reason (1905-6), expressam suas concepções que repercutiram na teoria da arte e o gosto artístico no início do século $X X$, segundo as quais a teoria ou estética da arte só podia ser considerada como parte de uma teoria geral de valores que abarcasse também o viver racional, a felicidade e a liberdade (Chilvers, 2001: 477). Assim, as ideias de Santayana ${ }^{7}$ complementam a opção narrativa do texto sobre padre Jesuíno, dando a Mário tranquilidade de estar apoiado em uma teoria ${ }^{8}$ do ponto de vista estilístico da escrita.

Jorge Coli, em texto crítico para a reedição da obra Padre Jesuíno do Monte Carmelo (2012), reforça a importância da atuação de Mário de Andrade como historiador da arte: "Mais do que 'crítica de artes plásticas', seu estudo sobre o Padre Jesuíno é um trabalho de historiador da arte. Trabalho exemplar, cujo rigor dos métodos empregados e escolhidos é surpreendente" (Coli, 2012: 319).

Se Telê Lopez (2002: 45) chamou-o de polígrafo para reforçar sua incrivel capacidade e versatilidade, Jorge Coli (2012: 320-321) destaca a sua capacidade de chegar a resultados, empregando métodos que se inter-relacionam e se complementam, sem se perder em considerações genéricas ou criar teorias pretensiosas. Para tanto, continua Coli, Mário teria usado o método de interpretação estilística de Giovanni Morelli (1816-1891), "do modo o mais minucioso, mas ainda percepções gerais, de ordem gráfica, cromática ou compositivas" (Coli, 2012: 321).

Morelli foi um crítico e historiador da arte de origem italiana, que, apesar de ter se formado em Medicina, começou a escrever sobre arte italiana em 1873. Concentrou seus trabalhos em pesquisas de atribuição de autoria de obras artísticas, sustentando que a maneira pela qual um artista trata os detalhes secundários de sua obra, como a representação das mãos ou das orelhas (e aqui seus estudos de anatomia tiveram inegável utilidade), seria equivalente a uma assinatura, e que, pelo estudo sistemático de tais detalhes, as atribuições poderiam ser feitas sem deixar margem a qualquer dúvida (Chilvers, 2001: 362). 
Igualmente como no caso de George Santayana, ausente do acervo da biblioteca de Mário de Andrade, hoje pertencente ao IEB USP, não localizamos nenhum título de autoria de Morelli, sendo necessário posteriormente verificar os possíveis caminhos do contato de Mário com o método que teve muita influência sobre diversos connoisseurs do final do século XIX e início do XX.

De acordo com Jorge Coli (2012: 321), a extensa análise que Mário de Andrade realiza do conjunto de doze pinturas sobre tela dispostas nas paredes laterais da capela-mor da igreja matriz de Nossa Senhora da Candelária em Itu, é essencialmente morelliana, pois ele destrincha minuciosamente, pormenores das figuras pintadas, como por exemplo, a posição das cabeças, formato dos narizes, massa muscular dos corpos e posição dos olhos.

Outro aspecto que reforça a argumentação apresentada por Coli, foi a inclusão por Mário de Andrade, de cinco desenhos copiados das telas de Itu por seu amigo, o arquiteto Lúcio Costa ${ }^{9}$, especialmente para o livro: um rosto de São João Batista ao lado de um de Jesus, colocados logo após um trecho que compara as soluções para o músculo do pescoço (Andrade, 1945: 62), e três rostos femininos - uma moça, Maria e Nossa Sra. do Carmo - comparando as linhas do nariz e as reentrâncias dos olhos (Ibidem: 68). O próprio Mário de Andrade realizou ao menos um desenho com o mesmo propósito de ver detalhes normalmente não considerados, como as sombras sistemáticas em torno da boca (Andrade, 2012: 365), mas que não foi incluído na primeira edição do livro.

Outro detalhe analisado por Mário de Andrade, e que se aproxima do método de Morelli, está no comentário sobre o estilo jesuínico de fazer as nuvens, presente no painel do Menino Jesus de Praga da igreja do Carmo de Itu:

O artista tratava suas nuvens com total despreocupação naturalística, e mesmo bastante cacoete. Acentuação violenta dos volumes, recusa sistemática de curvas largas e suaves, iluminação acentuada das orlas, que evoca um tanto as nuvens de Greco, sem qualquer intenção qualitativa da minha parte (Andrade, 1945: 89-90).

Sobre o conhecimento de Mário de Andrade a respeito de métodos de análises das imagens, merece destaque a presença em sua biblioteca de um exemplar do livro Conceptos fundamentales de la história del arte ${ }^{10}$, publicado em 1915 pelo historiador suíço Heinrich Wölfflin (1864-1945). O método apresentado, segundo o autor, permitiria uma análise sistemática do objeto artístico a partir da descrição de seus elementos compositivos e figurativos. Assim, seria possível reconhecer o mecanismo e o código de cada poética, excluindo a interpretação valorativa e intuitiva da obra de arte.

Para Wölfflin (1989), o objeto artístico se situa no conjunto da vida de uma época, portanto, a história da arte assumiria nesse contexto o significado de uma história de estilos e não de autores individuais. Para ele, todo estilo seria nada mais do que a construção coerente de elementos formais, distintos, em oposições binárias como: linear / pictórico; plano / profundidade; forma fechada / forma aberta; pluralidade / unidade; clareza / obscuridade (ou clareza absoluta / clareza relativa). Nas análises realizadas por Wölfflin em seu livro, contrapôs dois períodos subsequentes - Renascimento e Barroco, e, consequentemente, com categorias contrapostas: visão linear para o Renascimento, e visão pictórica para o Barroco. 
Considerando que Mário de Andrade ao escrever a biografia do padre pintor Jesuíno do Monte Carmelo pretendia apresentar uma categoria estilística nova para a arte brasileira, é interessante lermos com atenção o seguinte trecho no qual o autor analisa as pinturas sobre tela da capela mor da matriz de ltu:

Em certos quadros surpreende mesmo o vigor de gesticulação dialogada dos personagens, muito mais historiada e realista, e não há dúvida que estes quadros pertencem a um artista bom "compositor" dos seus assuntos. Os seus quadros respiram muito mais ação (desenho, grafismo) ao passo que outros respiram mais exposição (pintura, plástica) (Andrade, 1945: 56).

Ou seja, Mário apropria-se de um vocabulário muito próximo dos conceitos de Wölfflin: desenho, grafismo $=$ linear e pintura, plástica $=$ pictórica. $E$ repete um pouco mais à frente:

Mas embora, no caso nosso, o pintor mais duro, mais vertical, mais impositivo o dogmático se apresente mais pictoricamente plástico, e o outro mais expositivo e desenhístico, não se pode dizer que o primeiro seja melhor. Será mais espontaneamente plástico, talvez, mas esta espontaneidade deriva mais da ignorância e da timidez que duma superação estética (Ibidem: 58).

Na busca por indícios da tradição clássica no texto da biografia do padre Jesuíno, pudemos constatar diversas alusões a nomes de pintores europeus. A exemplo do que Mário de Andrade fizera no $A$ arte religiosa no Brasil (Andrade, 1993), surgem nomes como Leonardo da Vinci (1452-1519)11 quando ele analisa a pintura de Jesuíno para a Santa Ceia da capela-mor da matriz de Itu: "Convém reconhecer que alguns temas, os de banquetes, o batismo, os discípulos de Emaús implicavam para si mesmo um tal ou qual verticalismo, mas logo a gente se lembra da movimentação genial com que Da Vinci compôs o seu afresco da CEIA..." (Ibidem: 56 ).

Continuando a analisar as pinturas da capela-mor da igreja matriz de Itu, ao comentar as figuras da cena que ele chama de presépio, comparando-a com a apresentação de Jesus ao templo, Andrade invoca os pintores Giotto di Bondone (c.1267-1337) e Rafael Sanzio (1483-1520):

Poderíamos dizer destes dois grupos diversos de composições que julgo ver, que vai entre eles a mesma distância de espírito, de concepção e de estilo expositivo do assunto que, na Renascença italiana medeia entre um pintor dos Trezentos e um dos Quinhentos, entre um Giotto e um Rafael (Ibidem: 58).

Rafael Sanzio será citado duas vezes por Mário de Andrade no decorrer do livro, no trecho acima transcrito e, em seguida, na conclusão do livro, quando padre Jesuíno aparece associado com Peter Paul Rubens (1577-1640), em um comentário sobre as representações de figuras femininas, o conceito de belo e feio, associando indiretamente Renascimento e Barroco, tudo em uma única frase: "Na mulher, ele fixa uma fisionomia-receita que irá repisar por toda a vida. Um rosto que não é "feio", mas que não procura também um ideal de beleza feminina, como em Rafael ou Rubens, mas pretende apenas uma "convenção" de boniteza" (Ibidem: 138). 
Esta é a segunda vez que o nome de Rubens é destacado no livro. A primeira vez em que ele aparece é na análise da pintura do forro da capela-mor da igreja do Carmo da cidade de Itu, sendo associado a Giovanni Battista Tiepolo (1696-1770). Se anteriormente Rubens foi usado para falar do corpo feminino, aqui a relação se dá com a representação dos anjos pelo pintor Jesuíno:

Há mesmo dois desses anjinhos, o que segura a ponta do festão do lado esquerdo do painel central, e do outro, o que arregaça uma das dobras do festão junto ao anjo do grupo central nascido do entablamento, ambos tão audaciosos em seus movimentos, tão bem conseguidos em seus escorços, ao mesmo tempo que tão europeiamente bonitinhos, que discrepam muito de toda a obra angélica de Jesuíno. São muito "sabidos" demais. Serão cópias talvez.... Sugerem toda a malícia das decadências. Um pouco mais gordaços e róseos lembrariam Rubens. Tal como estão lembram Tiépolo. (Ibidem: 94-95)

Cerca de 25 anos antes, na crônica sobre a arte religiosa na cidade do Rio de Janeiro, quando Mário de Andrade comentou sobre os anjos entalhados na igreja conventual franciscana, Rubens também foi por ele citado, juntamente com Della Robbia, Donatello e Rafael (Andrade, 1993: 71). Ou seja, podemos considerar que 0 autor já havia estabelecido um repertório de artistas da arte ocidental que eventualmente são invocados em seus escritos.

$\mathrm{Na}$ conclusão de seu livro, Mário de Andrade afirma logo na primeira frase que a "obra de pintura do padre Jesuíno do Monte Carmelo deriva da concepção artística do Barroco europeu, imposta à nossa arte colonial. Mas não a exige. (...) e mesmo só relativamente como elemento comparativo de compreensão" (Andrade, 1945: 135). E para exemplificar essa afirmação, usou dois pintores que, assim como Rafael e Rubens, são por ele citados duas vezes: El Greco (1541-1614), pintor nascido em Creta que se estabeleceu na Espanha, e Rembrandt Harmenszoon van Rijn (1606-69), pintor holandês. Nela compara brevemente a tradição da pintura europeia com as lições de erudição que a arte colonial poderia ter deixado através da pintura do padre Jesuíno:

Uma personalidade impositiva, sem evidentemente a força plástica genial de um Greco ou de um Rembrandt, mas também insolúvel, se sobrepõe de tal maneira às tradições, lições de estilo da arte colonial erudita do tempo, que a temos de tomar, não liberta, mas esquecidamente do resto, para lhe apreciar a realidade (Ibidem: 135).

Novamente reafirma a que nem sempre a arte prescinde de tradições para atender ao seu tempo buscando como exemplo El Greco e Rembrandt:

Eu percebo, de preferência, um prescindir de tradições impostas, um não-ver necessário para necessariamente poder refletir exigências íntimas pessoais e sociais. Da mesma forma como um Greco não via os corpos da vida ou dos outros pintores quando desenhava os dele, ou Rembrandt não via a hora da tarde, para realizar sua Ronda da... Noite. Mas nós sabemos que a distribuição do claro-escuro era um ideal consciente em Rembrandt. 0 "ideal" que o padre Jesuíno do Monte Carmelo perseguia era consciente? Penso que não (Ibidem: 136).

Mário de Andrade não faz referência a pintores portugueses, e além de El Greco citado acima, o único representante citado da pintura espanhola é o sevilhano Bartolomé Steban Murillo (1617-1882), que foi 
extensamente conhecido fora de seu país, inclusive com grande circulação de cópias de suas pinturas pelo Novo Mundo. Seu estilo no tratamento de temas religiosos, principalmente das representações de Nossa Senhora, chegou a ser chamado de vaporoso, em função das figuras idealizadas, formas suaves, colorido delicado e doçura de ânimo e expressão (Chilvers, 2002: 367). É essa característica de delicadeza de sua pintura de rosto que é utilizada por Mário para falar do rosto de Maria pintada no quadro da capela-mor da igreja matriz de Itu, na cena da Natividade (ou Presépio como Mário se refere), criando um adjetivo específico:

Chega a ser necessária uma certa boa-vontade nossa para reconhecer, por exemplo, na Maria murilóide [grifo nosso] do PRESÉPIO, a mesma Maria do perfil dos outros quadros. (...) No caso da Maria do PRESÉPIO, tão discrepante com seu ar Murilo, das Marias de perfil mais altaneiras (...) (Andrade, 1945: 69).

Jorge Coli (2012: 323) considera que, no desenvolvimento do texto, há da parte de Mário de Andrade uma possivel "falta de interesse comparativo (afora, bem de raro, um Giotto e um Rafael alusivos, que se inserem no texto, tão genéricos como metáfora que se tornam de pouco significação)". A seu ver, isso se deve provavelmente a uma busca de uma alma nacional, junto ao fato de não haver referência a uma investigação das gravuras que guiaram a execução das pinturas. Além disso, Mário insistia no fato de que as obras brasileiras deveriam ser estudadas em âmbito brasileiro (Coli, 2012: 323).

No contexto desse estudo, consideramos que mesmo sendo breves as citações aos mestres da pintura europeia, elas são importantes como forma de validar as referências a um sistema de tradições. Sendo assim, a evocação da mitologia grega, ou seja, novamente uma pequena parte da cultura clássica, também deve ser destacada.

Para falar da transição de uma vida secular completa de Jesuíno em Itu, junto com sua esposa Maria Francisca e seus filhos, para uma vida celibatária, Mário de Andrade usa da figura mitológica da deusa Nêmesis, aquela que tem o sentido de justiça distributiva. Originariamente, a deusa grega infligia dor ou concedia felicidade segundo o que considerava justo. Portanto, por antonomásia, entende-se Nêmesis como a situação negativa que se segue a um período particularmente favorável, como ato de justiça compensatória. A ideia que subjaz ao termo é a de que o mundo deve obedecer a uma lei de harmonia, segundo a qual o bem deve ser compensado pelo mal em igual medida:

Jesuíno estava na força do homem e completado em sua vida secular. É a primeira obra de vulto que ele dedica à Virgem do Carmelo, da sua devoção. Jesuíno não sabe exatamente o que é sofrer. (...)

Houve um dia em que Nêmesis [grifo nosso] se lembrou de Jesuíno e lhe desmantelou o lar. Maria Francisca morreu. Jesuíno está com quatro filhos menores para sustentar e educar. Aceita ou procura as decorações em São Paulo e sofre uma vida irregularizada pelos contratempos (Andrade, 1945: 96).

Como última questão, não podemos deixar de citar a criação da tradição biográfica da história da arte consolidada pelas Vidas de Giorgio Vasari (1511-74) conforme escrito no início desse estudo. A ideia de um estudo de conjunto da história das artes agrupadas em biografias preocupava vários humanistas 
na primeira metade do século XVI. Se Vasari não a tivesse realizado, talvez outro a teria feito, e parece que a publicação de sua obra em 1550 desencorajou alguns pesquisadores de prosseguirem suas investigações, conforme aponta Lionello Venturi (1968).

O fato de a obra de Vasari ser uma sequência de biografias, segundo método inaugurado na Antiguidade, na qual a história era feita pelos indivíduos e não pelos povos, não fez dela uma coleção de retratos. Vasari não foi o primeiro a estabelecer a noção do desenvolvimento histórico, mas conseguiu fazer a narrativa dessas vidas se sucederem segundo uma gradação que the permite seguir até o fim uma linha mestra.

Quando se lê Vasari é preciso ter sempre em conta que para ele a sua concepção de história não deve ser verdadeira em absoluto, mas verossímil. Inúmeras são as suas fontes: usa seus predecessores, que ele conhece quase sempre em manuscrito, faz investigações por toda a Itália, por contatos diretos, e por correspondência; serve-se também dos guias que começam a ser publicados nas cidades da Itália. Consultou a literatura de história geral, mas também consultou diretamente os arquivos, como fez em Florença para o Libro Vecchio della compagnia dei pitturi Fiorentini ou o Libro dell'arte della Camila, insistindo diversas vezes, no decorrer de seu livro, no trabalho de pesquisa que esse the custou e as despesas que ocasionou. Teve ao seu lado Vicenzo Borghini, colecionador, que the orientou as pesquisas históricas e supervisionou a impressão da primeira edição.

Mário de Andrade realizou processo muito semelhante na constituição da biografia do padre Jesuíno: realizou muitas leituras específicas; entrevistou pessoas; contou com uma equipe de colaboradores formada por José Bento Faria Ferraz, seu secretário em São Paulo, e Mauro de Almeida em Itu, o fotógrafo Germano Graeser e o arquiteto Luis Saia; viajou para ver as obras do padre na cidades de Itu, Santos e São Paulo, pesquisou em arquivos de igrejas e da Cúria Metropolitana, recolhendo e coligindo documentos importantes para a redação, ou seja, consultou inúmeras fontes.

Havia na biblioteca de Mário, um livro de Vasari, uma espécie de separata da Vidas, um exemplar da vida do pintor florentino Sandro Botticelli (1544/5-1510)12. Isso não significa que ele se apoiou no método vasariano, mas que o conhecia.Na introdução, Mário de Andrade nos apresenta a descrição das partes do livro e a organização do conteúdo de cada uma delas, nomeando a primeira parte de Vida, e que em nosso entendimento, pode ser uma referência ao livro de Vasari:

Este trabalho está dividido em duas partes. Ou melhor, três: a Vida, a Obra e as Notas. (...) Eu sei muito bem que a Vida, do padre Jesuíno do Monte Carmelo, foi concebida quase como um "conto" biográfico. Interpretei dramaticamente. Mas as Notas provam, esclarecem ou justificam a minha interpretação, e repõem tudo no lugar. Quanto à Obra, reservei para ela o melhor do meu esforço, fazendo-a intencionalmente de ordem técnica, cerceando ao possivel os arroubos do entusiasmo (Andrade, 1945: 5).

Outra aproximação entre a obra do autor brasileiro e a do italiano, é a qualificação valorativa da vida dos artistas biografados: Vasari logo no título de seu livro - Le vite de piu eccellenti pittori, scultori ed architettori (1927), ou A vida dos mais excelentes pintores, escultores e arquitetos, em uma tradução 
literal, e Mário na introdução de sua obra: "A minha 'literatura', no caso, além da redação, consistiu em organizar, dar uma nova cronologia aos sucessos dessa Vida extraordinária” (Andrade, 1945: 5).

Diversos dos equívocos da obra de Vasari já foram colocados em evidência e discutidos, ela continua sendo o grande documento através do qual temos acesso à arte do Renascimento italiano. Continuamente retornamos ao autor, seja para criticá-lo ou para dar-lhe razão. Seu grande mérito, segundo Luiz Marques escreve na apresentação da primeira edição em português brasileira (Vasari, 2011), é se identificar com os seus biografados, o que transforma a sua leitura em obrigatória como entendimento e conhecimento do que foram os séculos XII a XVI para a arte italiana.

Nesse sentido, a afirmação de Jorge Coli (2012: 325) sobre o livro ressoa de modo semelhante:

Todo livro, de qualquer forma, não é comprometido por esses traços ao mesmo tempo pessoais e de época. No seu conjunto, é muito atual, sejam quais forem as conclusões que novas pesquisas e novas descobertas trouxerem sobre o padre pintor. Dentro todos os estudos escritos por Mário de Andrade, o Padre Jesuíno do Monte Carmelo é o mais rigoroso, acabado e atual.

Mário de Andrade, a nosso ver, identificou-se com o seu biografado. Conclui o texto com uma frase da Oração Fúnebre que o padre Diogo Feijó escreveu para o Jesuíno e que hoje também podemos incluir para o seu biógrafo: "engenho vivo, penetrante, atilado, talhado para melhores tempos; e que nascido em outra época mais feliz para a cultura das artes, seria capaz de propor modelos originais ao gosto $\mathrm{e}$ ao belo" (Andrade, 1945: 148-153).

O cruzamento da bibliografia sobre tradição clássica, história e estética da arte existente no acervo de livros que pertenceu a Mário de Andrade com as citações presentes no texto sobre a vida e obra do padre Jesuíno do Monte Carmelo, nos forneceu indicações de sua trajetória teórica-historiográfica na construção da biografia. Identificamos nas referências diretas e indiretas a estudiosos como Vasari, Reinach, Santayna, Morelli e Wölfflin, a busca por fontes teóricas sobre a tradição clássica, e nas citações aos mestres da pintura europeia como Tiepolo, Rafael ou Donatello, exemplos de atributos artísticos do legado clássico presentes no seu texto.

Mário de Andrade estava em sintonia com os estudos de história da arte, da cultura e da tradição clássica desenvolvidos em sua época e em diálogo com a emergência de novas concepções de saber decorrentes do modernismo. No esforço de estabelecer uma teoria vinculada à modernidade e aliada com a cultura clássica, buscou nas análises da obra do padre pintor Jesuíno do Monte Carmelo um modelo de tradição, enquanto que na apresentação da vida do padre, apresentou um projeto teóricometodológico para a historiografia da arte brasileira. 


\title{
Referências
}

ANDRADE, M. de. A arte religiosa no Brasil. Texto crítico Claudéte Kronbauer. São Paulo: Experimento/ Giordano, 1993.

Cartas de trabalho: correspondência com Rodrigo Melo Franco de Andrade (19361945). Brasília: Ministério da Educação e Cultura/ Secretaria do Patrimônio Histórico e Artístico Nacional/ Fundação Pró-Memória, 1981.

Padre Jesuíno do Monte Carmelo. Publicações do Serviço do Patrimônio Histórico e Artístico Nacional, n. 14. Rio de Janeiro: Ministério da Educação e Saúde, 1945.

Padre Jesuíno do Monte Carmelo. Texto crítico de Aline Nogueira Marques e Maria Silvia lanni Barsalini. Rio de Janeiro: Nova Fronteira, 2012.

CHILVERS, I. Dicionário Oxford de Arte. São Paulo: Martins Fontes, 2001.

COLI, J. O historiador da arte e o pintor Jesuíno do Monte Carmelo. In: Andrade, Mário de. Padre Jesuíno do Monte Carmelo. Texto crítico de Aline Nogueira Marques e Maria Silvia lanni
Barsalini. Rio de Janeiro: Nova Fronteira, 2012, p. 319-325.

KRONBAUER, C. Mário de Andrade: um texto de juventude. In: Andrade, Mário de. A arte religiosa no Brasil. Texto crítico Claudéte Kronbauer. São Paulo: Experimento/ Giordano, 1993, p.11-16.

LOPEZ, T. A. A biblioteca de Mário de Andrade: seara e celeiro da criação. In: ZULAR, Roberto (org.). Criação em processo: ensaios de crítica genética. São Paulo: Iluminuras/ FAPESP, 2002, p. 45-72.

VASARI, G. Le vite de piu eccellenti pittori, scultori ed architettori. Firenze: Adriano Salan, 1927.

Vida dos artistas. São Paulo: WMF/ Martins Fontes, 2011.

VENTURI, Lionello. História da crítica da arte. São Paulo: Estúdios Cor, 1968.

WÖLFFLIN, H. Conceitos Fundamentais da História da Arte: o problema da evolução dos estilos na arte mais recente. São Paulo: Martins Fontes, 1989.

\section{Notas}

\begin{abstract}
* Doutoranda da Faculdade de Arquitetura e Urbanismo da USP, Mestre em Artes pelo Instituto de Artes da UNESP e professora do curso de Design da Universidade Federal do Espírito Santo. E-mail: <myriamsalomao@usp.br>. ORCID: <https://orcid.org/0000-00027479-8612>.

${ }^{1}$ Panofsky, historiador da arte alemão conhecido pelas obras Estudos de iconologia (1939) e Significado nas artes visuais (1955), desenvolveu este tema no livro Idea: contribuição à história do conceito da antiga teoria da arte (1924), traduzido posteriormente para o português como Idea: a evolução do conceito do belo.

2 Winckelmann foi para Roma em 1755, onde se tornou bibliotecário do colecionador Cardeal Albani e logo estabeleceu-se como erudito e antiquário de renome europeu.

${ }^{3}$ Nos textos de $A$ arte religiosa no Brasil, Mário de Andrade refletiu e comentou sobre o Barroco enfocando-o em três crônicas: a primeira, cujo tema era o Triunfo Eucarístico de 1733, foi resultado de uma conferência realizada na Congregação da I.C. de Santa Efigênia e foi escrita em duas partes; a segunda, sobre a arte religiosa do Rio de Janeiro colonial e a terceira sobre a arte religiosa em Minas Gerais do século XVIII. Todos esses textos foram publicados no mesmo ano de 1920, nos números 49, 50, 52 e 54 da Revista do Brasil.

${ }^{4}$ Refere-se ao historiador e arqueólogo francês Salomon Reinach (1858-1932), mais conhecido por ter sido o defensor de Alfred Dreyfus no escândalo político do caso Dreyfus (1894-1906). Reinach fez valiosas descobertas arqueológicas nas décadas de 1880 e 1890 , foi membro da Society of Antiquaries de Londres e diretor do Museu de Saint-Germain-en-Laye, sua cidade natal. Há diversas colaborações de sua autoria na revista luso-brasileira Atlantida (1915-1920), da qual Mário de Andrade possuía alguns exemplares. ${ }^{5}$ Editado em Paris pela Hachette et Cie. em 1909, integra o acervo da biblioteca do Instituto de Estudos Brasileiros da USP.
\end{abstract}


${ }^{6}$ De 1963 a 1968, um projeto de pesquisa pioneiro coordenado pelo Prof. Dr. Antonio Candido de Mello e Souza, da Faculdade de Filosofia, Letras e Ciências Humanas da USP, ocupou-se do tombamento de títulos, do registro e de uma primeira classificação dos títulos da biblioteca de Mário de Andrade, quando ela ainda estava na própria residência na rua Lopes Chaves, no bairro da Barra Funda, São Paulo, portanto antes de sua transferência para o Instituto de Estudos Brasileiros no segundo semestre de 1968. Na ocasião, trabalharam no projeto Maria Helena Grenbeckie e Telê Ancona Lopez, que realizaram seus mestrados concluídos em 1967 na área de Teoria Literária e Literatura Comparada na FFLCH-USP a partir desta pesquisa.

${ }^{7} \mathrm{Na}$ biblioteca de Mário de Andrade não há nenhum exemplar de livro de George Santayana, mas existem os seguintes livros de Álvaro Lins, que integram a coleção no IEB USP: exemplar com dedicatória do autor para Mário de Andrade: Jornal de Crítica: 3. Série (1944); Jornal de Crítica: 2. Série (1943); exemplar com dedicatória do autor: Notas de um diário de crítica (1943); dois exemplares, sendo que, como era característico de Mário de Andrade, o exemplar autografado pelo autor e com dedicatória era preservado: Jornal de Crítica: 1. Série (1941); exemplar contendo anotações nas margens e dedicatória do autor: História Literária de Eça de Queiroz (1939). ${ }^{8}$ Poderíamos supor que a troca de conhecimento entre Álvaro Lins e Mário de Andrade a respeito de Santayana tivesse sido por cartas, pois os dois se correspondiam há alguns anos; mas a forma com que Mário constrói sua afirmativa lendo Álvaro Lins (Andrade, 1945: 5) condiz mais com a leitura de um livro. Essa questão será plenamente elucidada em momento oportuno.

${ }_{9}^{9}$ Apesar destes desenhos não estarem creditados na edição de Padre Jesuíno do Monte Carmelo de 1945, Maria Silvia lanni Barsalini traz essa informação no texto de apresentação para a edição de 2012, além de acrescentar ao final do livro, mais um desenho realizado por Lúcio Costa, mas não utilizado na edição de 1945 (Andrade, 2012: 371).

10 Título original: Kunstgeschichtliche Grundbegriffe. Exemplar em espanhol pertencente ao acervo da biblioteca do IEB: Enrique Wölfflin, traducido del alemán por J. Moreno Villa. 3.ed. Madrid: Espasa Calpe, 1936. Biblioteca de Ideas del Siglo XX n.7.

${ }^{11}$ Sobre Leonardo da Vinci, Mário de Andrade possuía um exemplar do livro Léonard de Vinci: ouvrier de l'intelligence, de Fred Bérence, editado pela Payot de Paris em 1938. Escrito por da Vinci, possuía a edição Traité de la Peinture, publicada pela De lagrave, Paris, 1934, e Textes choisis; pensées, théories, preceptes fables et facéties, publicada pela Mercure de France, Paris, 1929, sendo que 0 exemplar desse livro possuiu diversas anotações em suas margens.

12 Giorgio Vasari. Vita di Sandro Botticelli, con una introduzione. Milano: R. Bemporad, 1914 (exemplar da biblioteca de Mário de Andrade, atualmente no IEB USP).

Artigo recebido em março de 2020. Aprovado em abril de 2020. 